\title{
Calculating the profile of intermittent grinding wheel for the sharpening teeth of the broach
}

\author{
Vladimir Bogutsky ${ }^{1}$, Yurij Novoselov ${ }^{1}$, and Leonid Shron ${ }^{1, *}$ \\ ${ }^{1}$ Sevastopol State University, Universitetskaya st., 33, Sevastopol, 299053, Russia
}

\begin{abstract}
The article shows that during the grinding of complex profile blades of metal cutting tools from tool steels, unfavorable thermodynamic conditions are created in the cutting zone and, as a result, grinding burns and cracks occur on the surface of the polished workpiece. One of the methods of controlling the temperature in the cutting zone at the final grinding operations is the use of grinding wheels with a discontinuous surface. The method of calculating the profile of the discontinuous surface of the grinding wheel presented in the article makes it possible to determine its geometric parameters taking into account the wear resistance of the grinding wheel and the heat stress of the process of treatment. The results of the verification of the proposed technique in the production conditions are given which showed that the treatment of the teeth of the broaches with a grinding wheel with a discontinuous profile, in comparison with the machining of broaches according to the traditional technology, provides a higher quality of blade surfaces, while the process productivity, compared with the factory technology, increased by $20 \ldots 26 \%$.
\end{abstract}

\section{Introduction}

The high level of requirements for modern metal-cutting tools has caused a number of problems associated with the creation of high-performance technological processes that ensure the manufacture of tools with specified quality parameters that determine their functional suitability. The specified parameters are provided by changing the dimensions, shape, surface roughness, physical and mechanical properties of the material being processed.

Among the metal-cutting tools the special place is occupied by the shaped cutting tool round and flat broaches, solid and pre-assembled worm cutters, gear shaper cutters, etc. For their manufacture, mainly tool steels of the grades P6M5 (Russia), T11302M2 (USA), X82WMoCrV6-5-4 ( Germany, France), SKH51 (Japan), etc. [1-4, et al.].

In the process of grinding the metal-cutting tools of these steels with the surfaces of a complex profile and the non-linear contact zone with the surface to be treated (for example, broaching), unfavorable thermodynamic conditions are created in the cutting zone and, as a result, grinding burns and cracks appear on the surface of the polished workpiece, it is not possible to eliminate them in the subsequent finishing passages. It is difficult to detect these defects in production conditions. Therefore, when grinding the blades of metal cutting tools, it is necessary to select such processing modes and characteristics of the grinding wheel so

*Corresponding author: shronlb@mail.ru 
that the temperature in the contact zone does not reach the critical temperature points of the structural transformations. One of the methods for controlling the temperature in the cutting zone is the use of grinding wheels with a discontinuous surface [5-8, et al.]. So the problem of calculating the geometry of their profile becomes more urgent.

\section{Materials and methods of research}

According to [9-13], the time during which the temperature rises to the maximum value and stabilizes, for high-speed steels is $0.001 \ldots 0.01 \mathrm{~s}$. Such a time interval is commensurable with the period of rotation of the grinding wheel. It is obvious that the grinding process will be carried out with maximum thermal tension, if the period of thermal saturation is equal to the period of rotation of the circle. When a circle with a discontinuous working surface is used, the operating time of each cutting ledge will decrease in proportion to their number. The temperature during this period, not having reached the maximum value in the interval of passage of the depression, will decrease. If the operating time of one cutting ledge is less than the period of thermal saturation, irrespective of the grinding scheme and the material being processed, the intermittence of the process in all cases will ensure a decrease in the temperature in the contact zone [7, 10, 18 et al.].

The same degree of temperature reduction can be obtained with different combinations of lengths of the cutting ledges and cavities. This circumstance makes it possible to select the geometric parameters of circles with a discontinuous surface, taking into account the wear resistance of the circles and the heat stress of the process. With increasing wear of the wheel, its performance decreases due to a reduction in cutting speed.

Calculation of the profile of a grinding wheel with a discontinuous working surface includes the following steps:

1. Selection of characteristics and geometric dimensions of the abrasive tool. The choice of the characteristics of the grinding wheel depends on the design and purpose of the cutting tool, the material of its working part, the design and purpose of the grinding machine, the grinding modes. Apply circles of electrocorundum white 24A, 25A on ceramic and bakelite bonds with grain size F40...F30 hardness $\mathrm{H}, \mathrm{I}, \mathrm{J}$ and less often $\mathrm{K}, 7 \ldots 8$ th structure (ceramic bond) and J, K, L, 4...5th structure (on a bakelite bond) [14-17]. The diameter of the grinding wheel must be consistent with the dimensions of the broach and the angle of installation of the spindle grinding machine.

$$
D_{k} \leq \frac{D \cdot \sin (\delta-\gamma)}{\sin \lambda}
$$

where $D_{k}$ - is the diameter of the grinding wheel; $D$ - tooth diameter of the broach; $\delta$ - the angle of the spindle of the grinding machine; $\gamma$ - the front corner of the broach tooth.

2. Calculation of the temperature $T_{\max }$ in the cutting zone when grinding the teeth of the broach with a continuous circle, determining the temperature of the onset of phase transformations in the material of the $T_{c r}$ broach and the degree of temperature decrease $p=T_{c r} / T_{\max }$.

The maximum cutting temperature during grinding can be defined as $[17,18]$ :

$$
T_{\max }=q \sqrt{\frac{2 \cdot \tau}{\lambda \cdot c \cdot \rho}}
$$

where $q$ - is the heat flux density, $\mathrm{J} / \mathrm{s} \cdot \mathrm{m}^{2} ; \mathrm{c}$ - specific heat of the processed material, $\mathrm{J} /(\mathrm{kg} \cdot \mathrm{K})$; $\lambda$ - is the coefficient of thermal conductivity of the material being processed, $J \cdot K / s . m ; \rho-$ density of the material being processed, $\mathrm{kg} / \mathrm{m}^{3} ; \tau$ - processing time, $s$. 
The temperatures of the onset of phase transformations of Tcr (the temperature of the transition of martensite to perlite, point $A$ and the temperature of the transformation of perlite into austenite, point A1 in the iron-carbon diagram), when grinding quenched steels, vary with the carbon content of the steel, the composition of the alloying elements, and can be determined from [19] or calculated from the dependences [20]:

$$
T_{\text {cr }}=A=602 M_{0}^{0.15} \cdot V_{2}^{0.1} \quad T_{\text {cr }}=A_{1}=730+155 M_{0}^{0.08} \cdot V_{2}^{0.3}
$$

where $M_{0}$ - is the carbon content in the martensite, $\% ; V_{2}-$ the speed of movement of heat source, $\mathrm{m} / \mathrm{min}$.

3. Calculation of dimensionless parameter of cutting speed $u[5,10]$ :

$$
u=\frac{V_{u} \cdot \sqrt{D_{e} \cdot t_{f}}}{2 \alpha}
$$

where $V_{u}$ - rotation speed of workpiece, $m / s$; $D_{k}$-equivalent diameter, $m ; t_{f}-$ depth of microcutting, $m ; \alpha-$ the thermal diffusivity of the workpiece material, $\mathrm{m}^{2} / \mathrm{s}$.

For the case of grinding the teeth of the broach, the equivalent diameter is [21]

$$
D_{e}=\frac{D_{k} D}{D_{k} \sin \gamma-D \sin (\delta-\gamma)}
$$

and the dependence (3) takes the form

$$
u=0.5 V_{u} \cdot \sqrt{\frac{D_{k} \cdot D \cdot t_{f}}{\alpha^{2} \cdot\left[D_{k} \sin \gamma-D \sin (\delta-\gamma)\right]}} .
$$

4. Determining the coefficient value $v_{0}$. The value of coefficient $v_{0}$ is chosen according to table 1 [5] from condition

$$
1 \geq v>v_{0}
$$

where $v=l_{\text {led }} / l_{\text {cav }} ; l_{\text {led }}-$ length of the protrusion on the working surface of the grinding wheel, $m m ; l_{\text {cav }}-$ the length of the cavity on the working surface of the grinding wheel, $m m$. For the method of forming a discontinuous surface $l_{\text {led }}=l_{\text {cav }}$.

5. Determination of the Fourier criterion F01. The Fourier criterion is determined from the graphs (fig.1) $[10,22,23]$ or according to the following dependence using the coefficients given in table 1 .

$$
F_{01}=\frac{v-v_{0}}{A+B u}
$$

6. Calculation of the lengths of protrusions and valleys (for the chosen method of forming the discontinuous surface of the grinding wheel they are equal) and their number

$$
l_{\text {led }}=l_{\text {cav }}=\frac{V_{k} \cdot D \cdot d_{2} \cdot t_{f} \cdot F_{01}}{4 \alpha \cdot\left[D \sin \gamma-d_{2} \sin (\delta-\gamma)\right]} ; \quad Z=\frac{\pi D_{k}}{l_{\text {led }}+l_{\text {cav }}} .
$$

where $V_{k}$ - grinding wheel rotational speed, $\mathrm{m} / \mathrm{s} ; d_{2}$ - the distance from the axis to the midline of the tooth broach, $m$. 
7. Determination of the depth of the depressions. To determine the depth of the depression $h_{\text {cav }}$ consider the dimensional chain (fig. 2. (a)), according to which:

$$
h_{c a v}=\Delta R+\Delta h_{u}
$$

a

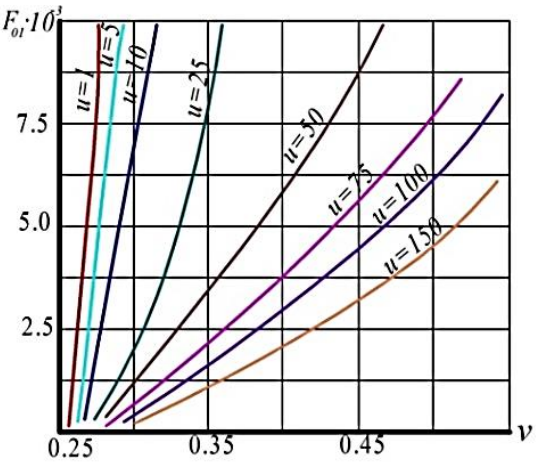

b

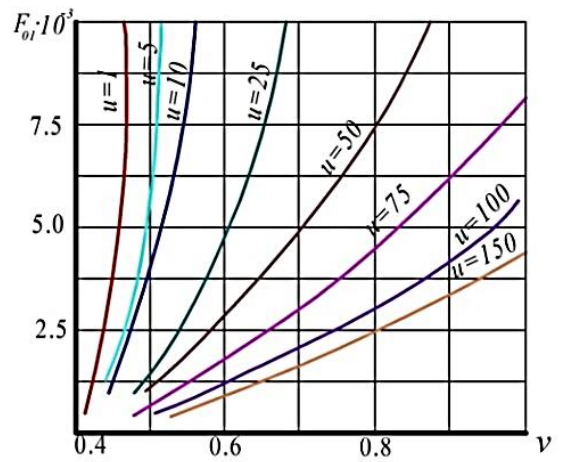

Fig. 1. The dependence of the criterion value from the Fourier transform of $v$ for different dimensionless velocities $u$ : $(a)$ - the degree of temperature decrease of $20 \%(P=0,8)$; (b) - degree temperature drop $30 \%(P=0,7)$.

The value of the defect layer on the surface of the circle $\Delta h_{u}$, for the case of straightening the abrasive wheel with diamond tools, according to [15] is related to the grain size of the grinding wheel $B_{g}$ by the relation

$$
\Delta h_{u}=(0.2 \ldots 0.25) B_{g}
$$

Hence the value of the layer removed during the editing

$$
h_{\mathrm{dr}}=(0.4 \ldots 0.5) B_{g}+\Delta R \text {. }
$$

Table 1. The coefficients for determining the Fourier criterion $F 01$.

\begin{tabular}{|c|c|c|c|c|c|c|c|c|c|}
\hline \multirow{2}{*}{$\begin{array}{c}\text { The coefficient of } \\
\text { temperature decrease } p\end{array}$} & & \multicolumn{3}{|c|}{$1,5 \geq u>1$} & \multicolumn{3}{|c|}{$90 \geq u>15$} & \multicolumn{3}{|c|}{$150 \geq u>90$} \\
\cline { 2 - 11 } & $A$ & $B$ & $v_{0}$ & $A$ & $B$ & $v_{0}$ & $A$ & $B$ & $v_{0}$ \\
\hline 0,8 & 1 & 0,32 & 0,25 & 1 & 0,32 & 0,27 & 1 & 0,32 & 0,28 \\
\hline 0,7 & 4 & 0,75 & 0,44 & 4 & 0,75 & 0,48 & 4 & 0,75 & 0,52 \\
\hline 0,6 & 5 & 1,70 & 0,68 & 5 & 1,70 & 0,71 & 5 & 1,70 & 0,74 \\
\hline
\end{tabular}

For straightening and profiling the circles, a straightening tool was used [24-25]. On fig. 2.(b) shows the profilogram of the transition zone of the cutting surface of the grinding wheel into the cavity. 

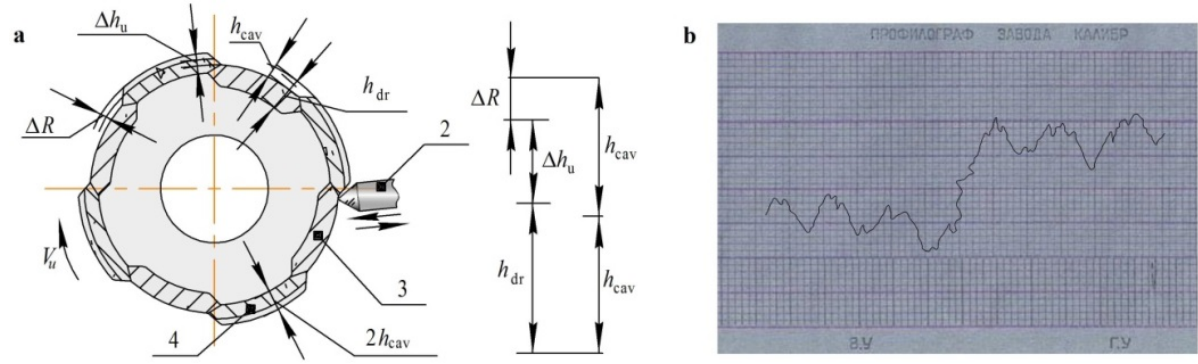

Fig. 2. (a) - dimensional chain of the circle re-profiling; (b) - profilogram of the transition zone of the cutting surface of the grinding wheel into the cavity.

8. Determination of the period of re-profiling of the grinding wheel with a discontinuous profile. The frequency of the changes in the grinding wheels is determined by the period of their stability, depends on many factors and is usually established on the basis of statistical data obtained under different grinding conditions.

To determine the re-profiling period, the following criteria can be used: increase to critical values of the contact temperature in the grinding zone and the emerging danger of occurrence of burns, microcracks or structural changes in the surface layer of polished blanks (parts); output of the dimensions of the part beyond the geometrical accuracy specified by the technical conditions; output indicators of roughness and waviness beyond the limits specified by the technical conditions; increased grinding power; the emergence of specific noise; occurrence of vibrations..

As a criterion for determining the period of re-profiling of the grinding wheel, the amplitude $A$ of the workpiece oscillations is chosen. [26-28]. The time for re-profiling was determined from the value of the oscillations of the strain-gauge centers, which were recorded by the oscilloscope DS1-102D. The grinding was stopped at $A \geq 4 \mu m$, preceding the burnt threshold. In fig. 3. shows the oscillograms of the intensity of oscillations when grinding wheel $1470 \times 8 \times 2524 A F 60 M 7 V$ with six ledges at the initial moment of work (a) and at the end of the period of durability (b), fig. 4. - the dependence of the wear value of the grinding wheel with a discontinuous profile for the period of its durability.

a

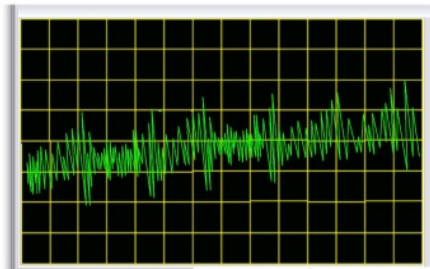

b

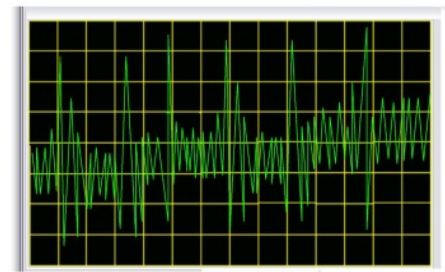

Fig. 3. Oscillograms of workpiece oscillations during grinding: (a) $60 \mathrm{~s}$; (b) $310 \mathrm{~s} ; \mu=0,065 \mu \mathrm{m} / \mathrm{mm}$ 


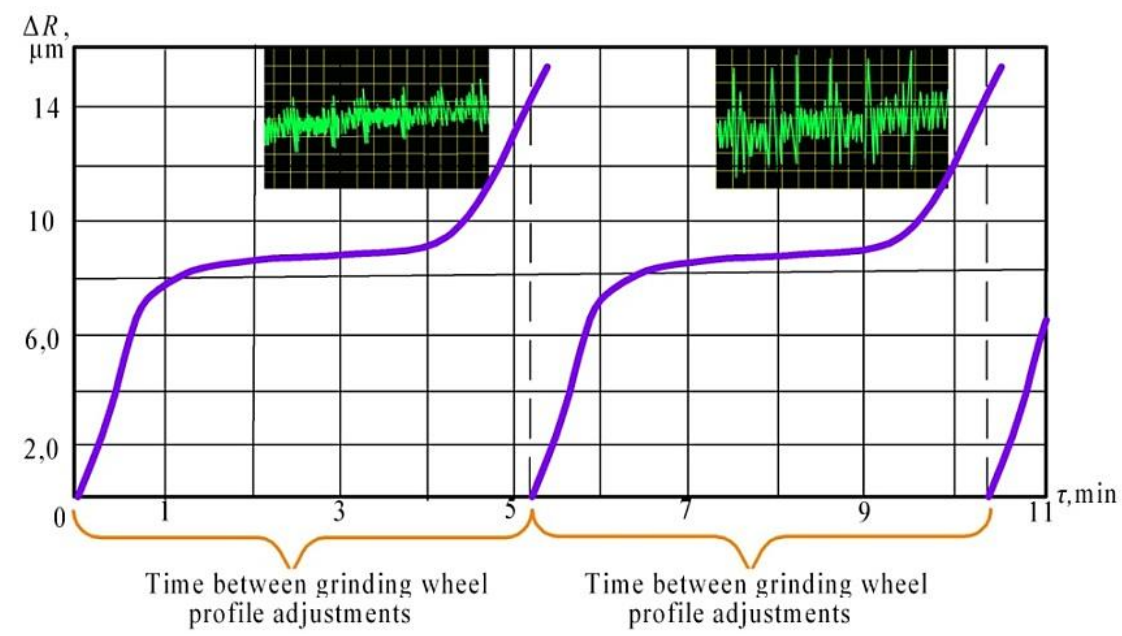

Fig. 4. Dependence of the wear value of the grinding wheel with a discontinuous profile $1470 \times 8 \times 25$ $24 A$ F60 M7 $V$ for the period of its durability.

Table 2 shows the comparative results of the quality of the surfaces of the teeth of broaches treated by the factory technology and a grinding wheel with a discontinuous profile.

Table 2. Comparative results of evaluation of the quality of the surface treatment of the teeth of broaches

\begin{tabular}{|c|c|c|c|c|c|c|c|}
\hline \multirow{3}{*}{$\begin{array}{c}\text { № } \\
\text { broaches in } \\
\text { the party }\end{array}$} & \multicolumn{4}{|c|}{$\begin{array}{l}\text { Deviations of the value of } \gamma \text { from the } \\
\text { nominal value }-\Delta \text {, arcmin }\end{array}$} & \multicolumn{3}{|c|}{ Surface roughness $-R a, \mu m$} \\
\hline & \multicolumn{7}{|c|}{ Grinding of the teeth of broach by factory technology } \\
\hline & Burns & $\max$ & $\min$ & $\begin{array}{c}\text { Dispersion } \sigma^{2}, \\
\operatorname{arcmin}^{2}\end{array}$ & $\max$ & $\min$ & $\begin{array}{c}\text { Dispersion } \\
\sigma^{2}, \mu m^{2}\end{array}$ \\
\hline 1 & + & 0,033 & 0,019 & $5,44 \times 10^{-6}$ & 0,36 & 0,22 & $4,0 \times 10^{-4}$ \\
\hline 2 & - & 0,030 & 0,015 & $6,25 \times 10^{-6}$ & 0,33 & 0,21 & $4,0 \times 10^{-4}$ \\
\hline 3 & + & 0,031 & 0,018 & $4,69 \times 10^{-6}$ & 0,34 & 0,23 & $4,44 \times 10^{-4}$ \\
\hline \multirow[t]{3}{*}{$\Sigma_{j}$} & + & 0,035 & 0,017 & $5,46 \times 10^{-6}$ & 0,343 & 0,22 & $4,14 \times 10^{-4}$ \\
\hline & \multicolumn{7}{|c|}{ Grinding of the teeth of the broach with a discontinuous profile } \\
\hline & Burns & $\max$ & $\min$ & $\begin{array}{c}\text { Dispersion } \sigma^{2}, \\
\min ^{2}\end{array}$ & $\max$ & $\min$ & $\begin{array}{l}\text { Dispersion } \\
\sigma^{2}, \mu m^{2}\end{array}$ \\
\hline 1 & - & 0,027 & 0,016 & $3,36 \times 10^{-6}$ & 0,32 & 0,22 & $2,25 \times 10^{-4}$ \\
\hline 2 & - & 0,031 & 0,018 & $4,1 \times 10^{-6}$ & 0,31 & 0,22 & $2,25 \times 10^{-4}$ \\
\hline 3 & - & 0,026 & 0,015 & $3,4 \times 10^{-6}$ & 0,29 & 0,20 & $2,25 \times 10^{-4}$ \\
\hline$\Sigma_{j}$ & - & 0,028 & 0,0163 & $3,62 \times 10^{-6}$ & 0,30 & 0,213 & $2,25 \times 10^{-4}$ \\
\hline$\Sigma_{i} / \Sigma_{j}$ & - & 1,75 & 1,1 & 1,5 & 1,14 & 1,04 & 1,66 \\
\hline
\end{tabular}

\section{Conclusion}

The presented technique for calculating the profile of a grinding wheel with a discontinuous surface allows one to select the geometric parameters of his profile, taking into account the wear resistance of the grinding wheel and the heat stress of the processing process.

The conducted production tests showed that the treatment of the teeth of the broaches with a grinding wheel with a discontinuous profile, in comparison with the machining of broaches 
according to the traditional technology, ensures the high quality of the tooth surfaces. All the teeth of broaches, polished with a discontinuous circle, along the roughness of the surface, the tolerance to the front corner, and the presence of burns corresponded to the requirements of the technological documentation. Compared with the machining of broaches according to the factory technology, the dispersion by the size of the grinding angles decreases by 1.5 times, by the surface roughness by 1.66 times. The productivity of grinding the teeth of the broaches compared with the factory technology, on average, increases by $20 . . .26 \%$.

\section{References}

1. U.M. Zubarev, Modern tool materials, PH Lan, St. Petersburg, (2008)

2. E.E. Feldshtein, M.A. Kornievich, Metal cutting tools: Design guide. Novoe znanie, Minsk, (2009)

3. D.T. Balaji, K. Nagarjuna, Design and manufacturing of square broach tool. IOSR Journal of Mechanical and Civil Engineering (IOSR-JMCE): 75-82, (2017)

4. J Paulo Davim, Machining and Machine-tools: Research and Development, Elsevier Science, (2013)

5. A.V. Yakimov, The intermittent grinding. Kiev, (1986)

6. K. Jeong-Du, K. Youn-Hee, J. Dong-Xie, L. Young-Seo, Development of discontinuous grinding wheel with multi-porous grooves. International Journal of Machine Tools and Manufacture Vol. 37, Iss.11, pp.1611-1624, (1997)

7. Y.A. Siziy, A.V. Fesenko, Y.N. Lubimiy, Heat accumulation in the surface layer of the details in a cycle of infeed grinding. Eastern-European Journal of Enterprise Technologies. № 7, pp. 61-63, (2013)

8. A.S. Lysak, V.G. Rakhcheev, Grinding of rails with discontinuous circles. Railway Track and Facilities, № 3, pp. 20-21, (2011)

9. K. Tsunemoto, S. Katsuo, O. Hideo, Grinding temperature within contact arc between wheel and workpiece in high-efficiency grinding of ultrahard cutting tool materials. Journal of Materials Processing Technology 136, pp. 39-47, (2003)

10. A.V. Yakimov, Optimization of the grinding process. Machinebuilding, (1975)

11. D.S. Gunwant, K.C. Harshal, R.R. Deshmukh, S.D. Deshmukh, Modeling and analysis of surface grinding for residual stresses in workpiece. International journal of mechanical engineering and technology, Vol. 3, Iss. 3, pp. 344-349, (2012)

12. J. Hwang, S. Kompella, S. Chandrasekar, T.N. Farris, Measurement of Temperature Field in Surface Grinding Using Infra-Red (IR) Imaging System, Journal of Tribology, Vol. 125, pp. 377-383, (2003)

13. W.B. Rowe, Thermal Analysis Of High Efficiency Deep Grinding. International Journal Of Machine Tools \& Manufacturing, Vol. 41, pp.1-19, (2001)

14. L. Rokyta, Testing of grinding wheels for tools manufacturing. Annals of DAAAM for 2011 \& Proceedings of the 22nd International DAAAM Symposium, Vol. 22, No. 1 pp. 1137-1138, (2011)

15. Abrasive and diamond material processing. Reference book / Edited by Reznikov A.N. Machinebuilding, (1977)

16. Choosing The Right Grinding Wheel. https://www.mmsonline.com/articles/ choosingthe-right-grinding-wheel. Accessed (2017) 
17. F.V. Novikov, Theoretical analysis of the technological opportunities to reduce cutting temperature during grinding. Technologies of information's are in education, science and production, № 3, pp. 88-95, (2015)

18. W.B. Rowel, M.N. Morganl, A. Batakol, T. Jin, Energy and temperature analysis in grinding. Transactions on Engineering Sciences, Vol. 44, pp. 3-22, (2003)

19. E.T. George, Steel heat treatment: Metallurgy and technologies. Second Edition. CRC Press, Boca Raton, (2006)

20. V.G. Lebedev, N.N. Klimenko, The kinetics of the temperature change of the critical points in the grinding of hardened steels. Proceedings ONPU, Iss. 2 (11), pp.59-62, (2000)

21. V.B. Bogutsky, S.M. Bratan, A.A. Yaroshenko, Modeling of processes of grinding and sharpening surfaces of teeth broaches. Vestnik SevNTU, Vol. 151, pp.14-23, (2014)

22. V.V. Poltavets, P.G. Matyukha, V.V. Gabitov, Optimization of diamond grinding conditions for steel R6M5F3 allowing for the process unsteadiness. Journal of Superhard Materials, Vol. 35, Iss. 6, pp.383-390, (2013)

23. N. Arunachalam, B. Ramamoorthy, Fourier Transform based texture measures for grinding wheel condition monitoring using machine vision, International Journal of Manufacturing Technology and Management Vol. 21, Iss. 1-2 DOI: 10.1504/IJMTM.2010.03429

24. V.B. Bogutsky, Y.K. Novoselov, et al., Device for grinding wheel dressing with intermittent work surface. Ukraine Patent 37655, (2008)

25. B.V. Bogutskiy, L.B. Shron, at al. Features of grinding wheel having a discontinuous surface. Scientific notes of the Crimean engineering and pedagogical University. Vol. 38. Technical Sciences. pp.56-6, 1(2013)

26. H. Zhang, B. Zhang, at al., Discuss on the acceptance criteria for acoustic rail grinding. ICSV24, pp. 1-8, (2017)

27. B.J. Dias, J.F. Meireles, L. Matias, A. Richard, Cylindrical parts circularity affectation by the grinding machine dynamic behaviour. 7th EUROMECH Solid Mechanics Conference, (2009)

28. L.V. Khudobin, A.N. Unyanin, Minimizing the brining of grinding wheels. Ulyanovsk, (2007) 